\title{
A new unsymmetrical dithienylethene contains a protecting aldehyde group
}

\author{
ShuYing $\mathrm{Li}^{1}$, RuiMin $\mathrm{Lu}^{1}$, DaoBin Zhang ${ }^{1^{*}}$ and Shouzhi Pu \\ ${ }^{1}$ Jiangxi Key Laboratory of Organic Chemistry, Jiangxi Science and Technology \\ Normal University, Nanchang 330013, P. R. China \\ *zhangdaobin2006@sina.com \\ Corresponding Author: DaoBin Zhang
}

Keywords: Photochromism, Diarylethene, Kinetics, Fluorescence switching

Abstract. A novel unsymmetrical isomeric photochromic dithienylethene, 1 - (2-methyl- 5- phenyl -3- thienyl)-2-\{[2-methyl-5-(3-1,3-dioxolane-4-methoxyl)phenyl]-3-thienyl]\}perfluorocyclopentene (10), was designed and synthesized. The photochromic and fluorescent properties of $\mathbf{1 0}$ were also studied. It is demonstrated that $\mathbf{1 0}$ exhibited excellent photochromism in acetonitrile solution accompanied with colorless solution changed to blue when irradiation with UV light

\section{Introduction}

In the past decade, various photochromic materials, such as diarylethenes [1], azobenzenes[2] and spirobenzopyrans[3], have been receiving much attentions. Between most photochromic compounds, diarylethene derivatives become outstanding representatives because they offer enhanced thermal stability of the two interconverting conformations [4], heightened fatigue resistance [5], and remarkable fatigue resistance. Therefore they can be potentially used in photochromic molecules in optical memories, switches, and actuators (or molecular machines) and so on [4-6]. Meanwhile, diarylethenes based on phenyl groups have aroused wide concern because they can increase the conversion efficiency and the absorptance of photochromic molecule at the photostationary state (PSS) [7]. Herein, we report a new unsymmetrical 10 with phenyl group and a protecting aldehyde group which could achieve deprotection and then extend the moleculer for other applications. The photochromic and fluorescent properties of 10 in solution were presented here.

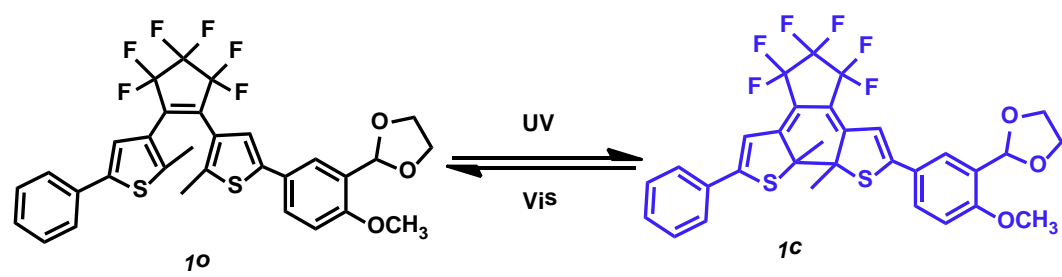

Scheme 1. Photoisomerization of 10

\section{Experiments}

Synthesis of 1o. As shown in Scheme 2, 3- Bromo- 2- methyl- 5-( 3-formyl -4 - methoxylphenyl) thiophene (1) and 3-Bromo-2-methyl-5-phenyl-3-thiophene (2) were obtained through Suzuki coupling reaction [8], (1-Fluorine-2-methyl-5-phenyl-3-thiophene)perfluorocyclopentene (3) was synthesized from 2 consistent with the previous literature [9]. then the formyl was protected with glycol to generate compound 4. Finally, compund 1o was obtained by addition with 3 to the lithiation of 4 in THF at 195K [10]. The compound 10 was characterized by ${ }^{1} \mathrm{H}$ NMR spectroscopy. ${ }^{1} \mathrm{H}$ NMR (400 MHz, CDC1 13 , TMS): $\delta 1.94$ (s, 6H), 3.86(s, 3H), 4.02 (t, 2H, $J=6 \mathrm{~Hz}$ ), $4.13(\mathrm{t}, 2 \mathrm{H}, J=6 \mathrm{~Hz}), 6.13(\mathrm{~s}, 1 \mathrm{H}), 6.88(\mathrm{~d}, 1 \mathrm{H}, J=4 \mathrm{~Hz}), 7.19(\mathrm{~s}, 1 \mathrm{H}), 7.28(\mathrm{~d}, 2 \mathrm{H}, J=12 \mathrm{~Hz}), 7.36$ (t, $2 \mathrm{H}, J=8 \mathrm{~Hz}), 7.46-7.49(\mathrm{~m}, 1 \mathrm{H}), 7.52(\mathrm{~s}, 1 \mathrm{H}), 7.54(\mathrm{~s}, 1 \mathrm{H}), 7.71(\mathrm{~d}, 1 \mathrm{H}, J=4 \mathrm{~Hz})$. 


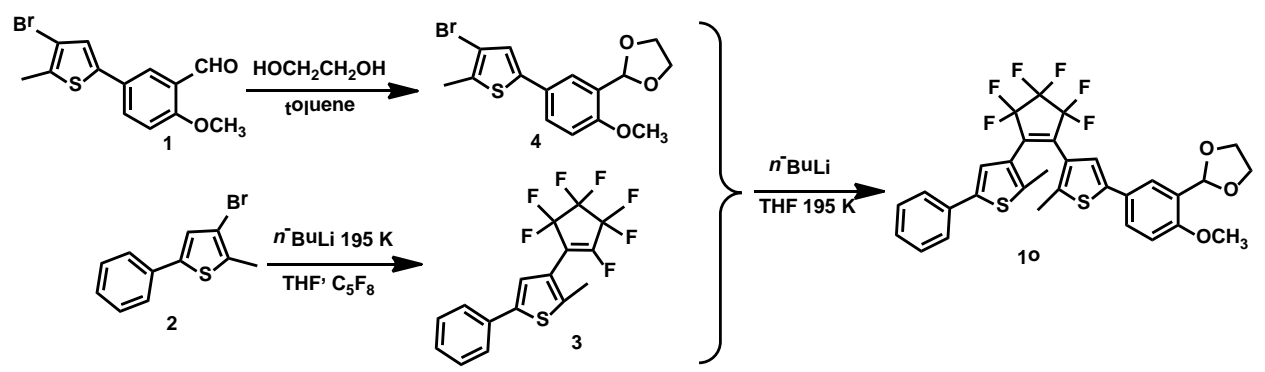

Scheme 2. Synthesis of 10

\section{Results and discussion}

Photochromic studies. The absoption band centered at $289 \mathrm{~nm}\left(\varepsilon, 3.00 \times 10^{4} \mathrm{~L} \mathrm{~mol}^{-1} \mathrm{~cm}^{-1}\right)$ of 10 was ascribed to $\pi \rightarrow \pi^{*}$ transition. Upon irradiation with $297 \mathrm{~nm}$ light, the band centered at 289 $\mathrm{nm}$ gradually decreased, and a new absorption band centered $592 \mathrm{~nm}\left(\varepsilon, 1 \times 10^{4} \mathrm{~L} \mathrm{~mol}^{-1} \mathrm{~cm}^{-1}\right)$ progressively increased due to the cyclization of 1 o to produce ring-closed isomer 1c.. Meanwhile, the colorless solution of 1o turned to blue. On the other hand, the blue solution of 1c turned to colorless and the UV-vis absorption spectra of 1c displayed reversed changes to 1o upon irradiation with visible light $(\lambda>500 \mathrm{~nm})$ of $1 \mathrm{c}$ soltuon.

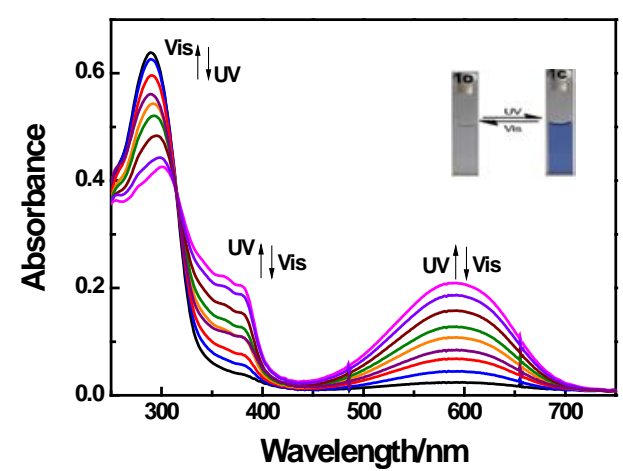

Fig. $1 \mathrm{UV}$-vis absorption spectral changes of 10 in acetonitrile $\left(2.0 \times 10^{-5} \mathrm{~mol} \mathrm{~L}^{-1}\right)$ upon alternating irradiation with UV and Vis light.

Photochromic reaction kinetics studies In order to investigated the relationships between the absorbance and exposal time, we studied the cyclization/cycloreversion kinetics of 10 in acetonitrile solution by UV-vis spectra (Fig. 2). As shown in Fig. 2, for both cyclization and cycloreversion reactions of 10, the absorbance and exposal time formed good linear dependence. It well know that the gradient of line can reflect reaction rate constant $(\mathrm{k})$.As result, the cyclization process of 10 in acetonitrile is division in the zeroth order reaction and the cycloreversion reaction belong to the first order reaction during the cycloreversion of $1 \mathrm{c}$ in acetonitrile.
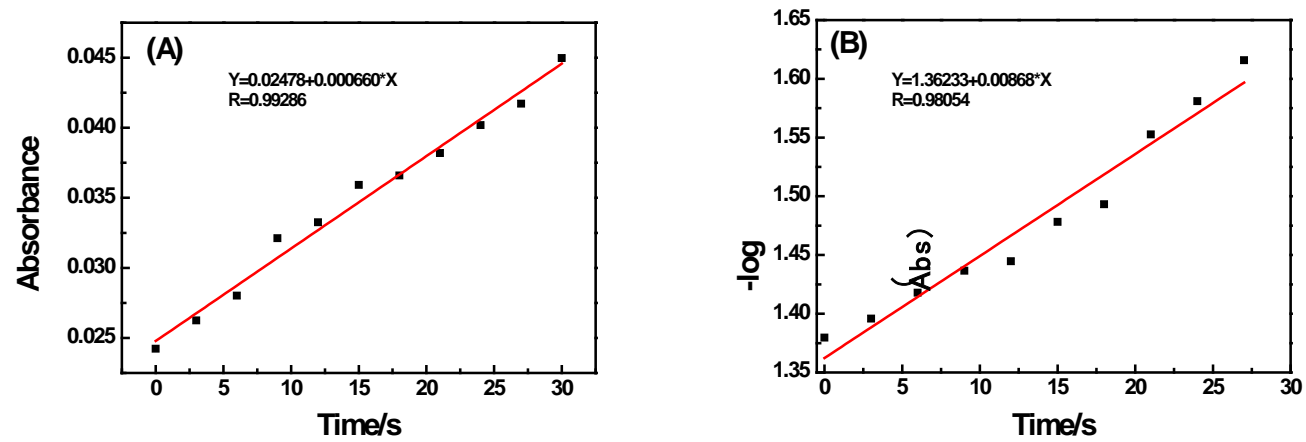

Fig. 2 The cyclization (A) and cycloreversion (B) kinetics of 10 in acetonitrile $\left(2.0 \times 10^{-5} \mathrm{~mol} \mathrm{~L}^{-1}\right)$.

Fluorescent studies Fluorescence switching of diarylethene can be used in molecular-scale optoelectronics, and the application of many diarylethenes has been reported [11-15]. Fluorescence 
spectra of 10 were measured at room temperature using a Hitachi F-4600 spectrophotometer in acetonitrile solution. From Fig. 3, the lower-fluorescent ring-closed species 1c was produced upon irradiated by $297 \mathrm{~nm}$ light, and the band centered at $483 \mathrm{~nm}$ continually decreased in emission intensity due to the photocyclization reaction $1 \mathrm{o} \rightarrow 1 \mathrm{c}$. Instead, if irradiation by visible $\operatorname{light}(\lambda>500$ $\mathrm{nm}), 1 \mathrm{c}$ changed into 10 accompanied with the original fluorescence spectrum recovered.

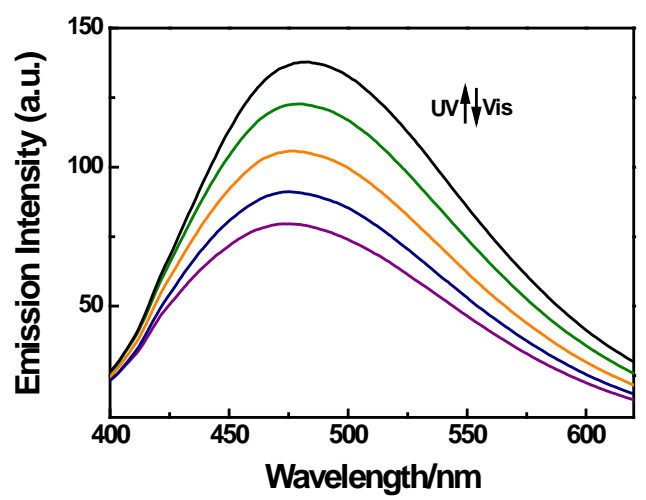

Fig. 3 Fluorescence spectral changes of 10 in acetonitrile upon irradiation with UV and Vis light

\section{Conclusion}

A new unsymmetrical photochromic diarylethene 10 was synthesized. It is a reversible transformation of a compound between two isomers owning different absorption spectrum induced by UV-Vis light. The studies of photochromic properties and the kinetic reactions in acetonitrile solution illustrated that 10 exhibited predominantly reversible photochromism. At the same time, the diarylethene can used as a fluorescent switchable molecule.

\section{Acknowledgment}

The authors are grateful for the financial support from the National Natural Science Foundation of China (21362013, 51373072)

\section{References}

[1] T. Hirose, K. Matsuda, M. Irie: The Journal of organic chemistry. Vol. 71 (2006) no. 20:7499-7508.

[2] W. Feng, K. Huang, M. X. Wang: Chinese Physics, vol. 14 (2005) no. 2, p. 306.

[3] G. Berkovic, V. Krongauz, V: Chemical reviews, vol. 100 (2000) no. 5, p. 1741-1754.

[4] M. Irie, Chemical Reviews: vol. 100 (2000) no. 5, p. 1685-1716.

[5] H, Tian, S, Yang: Chemical Society Reviews, vol. (2004) no. 2, p. 85-97.

[6] K. Higashiguchi, K. Matsuda, N. Tanifuji, et al: Journal of the American Chemical Society, vol. 127(2005) no. 25, p. 8922-8923.

[7] S. Hermes; G.Dassa, G.Toso, A. Bianco: Tetrahedron Letters, vol. 50 (2009) no.14, p. 1614-1617.

[8] S. Pu, H. Li, G. Liu, et al: Tetrahedron, vol. 67 (2011) no.7, p. 1438-1447.

[9] G. Liu, M. Liu, S. Pu, et al: Tetrahedron, vol. 68 (2012) no.10, p. 2267-2275.

[10]Z.P. Tong, S.Z Pu, S.Q Cui: Trans Tech Publications, vol. 399 (2011) p.1119-1122.

[11] C.C. Corredor, Z.L. Huang, K.D. Belfield: Advanced Materials, vol. 18 (2006) no. 21, p. 2910-2914. 
[12] Y. Zou, T.Yi, S.Z. Xiao, et al: Journal of the American Chemical Society, vol. 130 (2008) no. 47, p. $15750-15751$.

[13]T. Fukaminato, T. Kawai, S. Kobatake, et al: The Journal of Physical Chemistry B, vol. 107 (2003) no. 33, p. 8372-8377..

[14] S. Xiao, T. Yi, Y. Zhou, et al: Tetrahedron, vol. 62 (2006) no. 43, p 10072-10078.

[15] M.F. li, G.H. Mehl: Chemistry-A European Journal, vol. 10 (2004) no. 20, p. 5243-5250. 